\title{
A SOCIOLOGIA DE GRAMSCI
}

\section{Oliveiros S. Ferreira}

É preciso cuidado com as palavras quando se discute um tema como a "Sociologia de Gramsci". Não se trata, como poderá parecer, de dizer que Gramsci tenha constituído, a partir dos Cadernos do cárcere, uma teoria sociológica. Cuida-se, tão simplesmente, de procurar ver aquilo que, neles, indica que o pensamento do autor estava em consonância com uma certa maneira de analisar a realidade social que se chamava, à época e hoje, de "sociologia". Ousaria acrescentar - levando em conta a opinião daqueles que não vêem Gramsci preocupado com a sociologia, mas apenas com a ciência política - que não poderemos compreen-

* Comunicação apresentada na reunião da Anpocs, Caxambu, 2005.

Artigo recebido em novembro/2005

Aprovado em junbo/2006 der seu pensamento se não atentarmos para o cuidado que tem em estabelecer, na construção de boa parte dele, os fundamentos sociais das situações que analisa. Diria, mesmo, que ele estabelece alguns cânones para a análise que só podem ser tidos por sociológicos, pouco importando a que escola possamos pretender filiá-lo.

Entretanto, não se deve concluir que Gramsci não tenha cuidado maior com a ciência política ou coisa que a isso se assemelhe. O importante é notar que já no Caderno 11, $₫ 25$, o autor deixa claro que a sociologia pode ser vista como ciência da história e da política. É, essa, uma passagem curiosa, porque nela a "sociologia" é transmutada em "filologia", que em dicionário da língua italiana editado em 1924 é dada, também, como "ciência de estudos especiais". Nesse texto lê-se que o

[...] estudo [da filosofia da práxis] pode dar lugar ao nascimento da "filologia" como método de erudição na verificação dos fatos particulares e ao 
nascimento da filosofia entendida como metodologia geral da história. [...] Negar que se possa construir uma sociologia, entendida como ciência da sociedade, isto é, como ciência da história e da política, que seja algo diverso da filosofia da práxis, não significa que não se possa construir uma compilação empírica de observações práticas que ampliem a esfera da filologia, tal como esta é entendida tradicionalmente. Se a filologia é a expressão metodológica da importância que tem a verificação e a determinação dos fatos particulares em sua inconfundível "individualidade" é impossível excluir a utilidade prática da identificação de determinadas "leis de tendência" mais gerais, que correspondem, na política, às leis estatísticas ou dos grandes números, que contribuíram para o progresso de algumas ciências naturais (Gramsci, 1999, p. 146).

Ao lado dessa observação, segundo a qual muito do que se lê nos Cadernos pode e deve ser visto como um correto emprego de conceitos da sociologia, convém acrescentar outra: os Cadernos devem ser vistos como obra completa, por mais que se deva respeitar a opinião dos que a consideram fragmentada e escrita com todos os cuidados que Gramsci deveria tomar tendo em vista a censura. Afirmo que se pode e se deve tê-la como completa porque só dessa perspectiva é que compreenderemos a razão pela qual boa parte dos textos foi revista no decorrer do tempo que passou na prisão, ao passo que há uma pequena porção que se encontra em redação única. A apresentação gráfica dos Cadernos, respeitando a cronologia de sua escrita, permite a conclusão de que estamos diante de uma obra in fieri - e a edição de Gerratana leva a essa impressão. Se, porém, tivermos o cuidado de eliminar parágrafos menores, de circunstância, que encontramos em todos os Cadernos e unirmos os que de fato concernem aos títulos com que as anotações são apresentadas, teremos textos que expõem, acabadas, as mesmas proposições. $\mathrm{Na}$ verdade, é preciso considerar que há, nos Cadernos, textos de circunstância, teórica e metodologicamente de importância menor, e que apenas indicam a preocupação de Gramsci em atualizar-se em relação ao que se escrevia e se pensava fora dos muros da prisão.

Sem dúvida, as considerações que tece sobre o que seja a hegemonia e como ela se exerce - da mesma maneira que a respeito do que sejam sociedade civil e sociedade política, para não dizer o Estado e o papel dos intelectuais - permitem que se examinem os Cadernos como se a obra inconclusa fosse. Não sou o primeiro, entretanto, a insistir em que estamos diante de uma obra completa. Ainda que reconhecendo o "caráter fragmentário de seus escritos”, Gregorio Bermann, no prólogo a uma edição argentina das Cartas do cárcere, não deixou de afirmar que "circula através de todos esses fragmentos um pensamento profundamente unitário, coerente, maduro, organizado. Nem sequer a necessidade de passar pelas redes de uma censura mais do que zelosa o impede de expressar tudo o que pensa" (Gramsci, 1950, p. 10).

É preciso reconhecer, sem dúvida, que Gramsci apresenta sobejas razões para que seus textos sejam vistos como "fragmentados", tais as variantes que encontramos, às vezes no mesmo Caderno, sobre o mesmo conceito. Mas pergunto: Não poderíamos tomar essas variantes - que têm permitido as mais diferentes e às vezes contraditórias interpretações do que se encontra nos Cadernos - como se fossem uma obra musical, "variações sobre um mesmo tema", como "hegemonia", "sociedade civil", "sociedade política" ou "Estado", Marx ou Lênin, pouco importa, e como tal parte de uma só obra? O importante, quando tomamos as "variações" é saber qual o tema e sua autoria. Creio que podemos, sem receio de errar ou abusar da licença literária, dizer que o tema em torno do qual tece suas variações é o da hegemonia, de Lênin.

Dessa perspectiva - e admitindo que esse é o tema que o interessa, tomado de Lênin como expressamente afirma -, teremos que a hegemonia é um fato político, sem dúvida, mas que não pode ser compreendido no que seja, nem na forma em que se exerce, se não considerarmos a sociedade em que se apresenta e a articulação de seus segmentos. Em outras palavras, a hegemonia, como fato político, só pode ser exercida se houver condições sociais que permitam a um grupo social impor sua concepção do mundo aos demais. Essa observação leva a outra: ao estabelecer que a luta pela hegemonia se dá entre grupos sociais com concepções do mundo diferentes, Gramsci automaticamente remete ao campo da cultura, que não pode ser compreendido e analisado se descurar- 
mos da interação sempre presente entre sociedade e cultura. Com isso quero dizer que a luta pela hegemonia se dá entre visões de cultura e não de civilização - Kultur e não Zivilisation. É no campo da cultura que devemos fixar nossa atenção, nunca perdendo de vista a lição de Mannheim sobre como se pode diferençar uma época de outra (portanto, uma ideologia geral do período) pela comparação dos diferentes estilos artísticos que se sucedem: o barroco, o clássico, o romantismo, o impressionismo, o cubismo, o modernismo etc. Cultura, em suma.

Se considerarmos que Gramsci pode ser lido - e a meu ver é uma leitura profícua - como sociólogo será mais fácil compreender o que pretende transmitir. Em primeiro lugar, voltemos a Marx, que o inspirou e sobre cujos conceitos trabalhou, mascarando "marxismo" sob o nome de "filosofia da práxis".

O voltar a Marx não é um recurso de retórica: os pensadores de meados dos anos de $1840 \mathrm{em}$ diante tinham igual postura intelectual diante dos fatos políticos, qual seja, de que só podem ser explicados se atentarmos para suas raízes sociais. Não é preciso dar um passo atrás até os idéologues do período napoleônico, mas não seria demais ressaltar que as revoluções e as convulsões sociais que esses pensadores testemunharam, quando não delas participaram, condicionou essa maneira de ver, que depois se concretiza em Comte e avança com Durkheim. A filosofia da práxis, quando formulada no século XIX, é a visão sociológica dos fatos políticos "à esquerda". Ou as lições que estão nos Grundisse, afora a insistência em referir-se sempre às condições sociais de existência, a idéia da infra-estrutura determinando as superestruturas não são a melhor demonstração da tese que sustento? Nos Grundisse, Marx já deixava claro que o estudo de uma sociedade deveria começar pelo de sua morfologia. E, no Manifesto comunista, encontramos uma perfeita demonstração de como é a morfologia social que permite a transformação do confronto entre o proletário individual contra o patrão individual numa luta de classes. Nacional por definição.

Não é apenas em Gramsci, mas também nos autores socialistas do século XX, que encontramos a preocupação de ligar os fatos políticos à morfologia social. Talvez o melhor exemplo seja o de Trotsky em 1905, em que se registra que "o desenvolvimento econômico [na Rússia era] extremamente lento por causa das condições desfavoráveis criadas pela natureza do país e pela dispersão da população, [o que] criava obstáculos para o processo de cristalização social e colocava toda a nossa história em grande atraso" (Trotsky, 1948, p. 23).

No Caderno 6, \ 102, Gramsci estabelece, poderíamos dizer, as regras para estudar os camponeses e a vida no campo. É de notar a riqueza de pormenores com que cerca a aproximação do tema: desde as condições materiais de vida, como habitação, alimentação, alcoolismo e práticas higiênicas, passando por taxas de natalidade, mortalidade infantil e nascimentos ilegítimos até a situação das mulheres ("mudança das mulheres para os serviços domésticos"), sem deixar de relacionar as alterações na propriedade e, curiosamente, mas indicativo de uma mentalidade desejosa de apanhar todas as variações da vida comum, os problemas de religião e os crimes de caráter econômico e aqueles de sangue (Gramsci, 2002, p. 256).

Para a correta compreensão de como se estabelece e é exercida a hegemonia, é importante conhecer como se estrutura a sociedade. No mesmo Caderno 6, $₫ 136$, ele se ocupa desse tema:

Assinalei de outra feita que, numa determinada sociedade, ninguém é desorganizado e sem partido, desde que se entendam organização e partido num sentido amplo, e não formal. Nesta multiplicidade de sociedades particulares, de caráter duplo - natural e contratual ou voluntário - uma ou mais prevalece relativamente ou absolutamente, constituindo o aparelho hegemônico de um grupo social sobre o resto da população (ou sociedade civil), base do Estado compreendido como aparelho governamental-coercitivo (Idem, 2000a, p. 253).

Essa passagem traz à memória lições de Rousseau no artigo "Economia política" e de Tönnies em Comunidade e sociedade, especialmente quando analisa as "sociedades particulares" e aquelas "naturais e contratuais ou voluntárias".

As sociedades, convém lembrar, não se caracterizam apenas por ser compostas de outras menores, naturais ou contratuais; podem ser vistas, 
igualmente, da perspectiva de "cidade" e "campo", do "urbano" e do "rural". É importante observar, na distinção que Gramsci estabelece entre um tipo de organização social e outro, que ele insiste na idéia de que as "relações entre população urbana e população rural não são de um só tipo esquemático, especialmente na Itália”. Segue-se, daí, que é "preciso, portanto, estabelecer o que se entende por 'urbano' e 'rural' na civilização moderna e quais combinações podem resultar da permanência de formas antiquadas e retrógradas na composição geral da população estudada do ponto de vista de sua concentração maior ou menor". A análise, neste parágrafo 26 do Caderno 19, não apenas é sutil, como esclarecedora do que pretendeu dizer quando se referiu à maior ou menor concentração populacional numa cidade. Veja-se o trecho seguinte:

A concentração da população em centros nãorurais, quase o dobro em relação à França, demonstraria que existe na Itália duas vezes mais industrialização do que na França? Na Itália, a urbanização não é, nem sequer "especialmente", um fenômeno de desenvolvimento capitalista e da grande indústria. Nápoles, que foi por muito tempo a maior cidade italiana e continua a figurar entre as maiores, não é uma cidade industrial; nem mesmo Roma, a atual maior cidade italiana, é industrial. No entanto, até nestas cidades, de tipo medieval, existem fortes núcleos de populações do tipo urbano moderno; mas qual é sua posição relativa? Eles estão submersos, comprimidos, esmagados pela outra parte, que não é do tipo moderno e é a grandíssima maioria. Paradoxo das "cidades do silêncio" (Idem, 2002, pp. 87ss.).

A questão que se apresenta, então, é distinguir o "tipo urbano moderno" do "tipo não-moderno"; a partir dessa distinção é que poderemos compreender por que Nápoles, Roma e até mesmo cidades da Itália Meridional e Setentrional podem ser chamadas de "cidades do silêncio". É em "Americanismo e fordismo" que talvez se encontre a resposta para essa questão da maior importância quando se pretende ver Gramsci como sociólogo. No Caderno 22, \2, lemos o seguinte:

O chamado "mistério de Nápoles". [...] Goethe tinha razão ao demolir a lenda do lazzaronismo orgânico dos napolitanos ao sublinhar que, pelo contrário, eles são muito ativos e laboriosos. Mas a questão consiste em ver qual é o resultado efetivo dessa laboriosidade: ela não é produtiva e não se destina a satisfazer as necessidades e as exigências de classes produtivas. Nápoles é a cidade onde a maior parte dos proprietários rurais do Sul (nobres e plebeus) gasta a renda da terra. É em torno de algumas dezenas de milhares dessas famílias de proprietários, de maior ou menor importância econômica, com suas cortes de servos e lacaios diretos, que se organiza a vida prática de uma significativa parcela da cidade, com suas indústrias artesanais, com suas profissões ambulantes, com a enorme pulverização da oferta imediata de mercadorias e serviços aos desocupados que circulam pelas ruas. [...] A indústria "produtiva" (no sentido de que cria e acumula novos bens) é relativamente pequena, embora Nápoles seja incluída nas estatísticas oficiais como a quarta cidade industrial da Itália, depois de Milão, Turim e Gênova (Idem, 2001, p. 244).

Pode deduzir-se, desse trecho, que a "maneira nobre de viver" opõe-se à criação e à acumulação de novos bens, e que é este tipo de produção - o modo de reprodução ampliada do capital - que caracteriza o "moderno" e o "urbano". De fato, assim será se tivermos em mente a caracterização de Schumpeter sobre o capitalismo como indutor de um maior individualismo, uma maior racionalidade e uma maior democratização das condutas - o que condiz com as caracterizações do "urbano" feitas por diversos sociólogos.

A sociedade que Gramsci tem presente é, pois, composta de diferentes grupos sociais, e nela convivem diferentes modos de produção, diferentes tipos de condutas sociais e diversas culturas. É, em si, uma sociedade contraditória. Essa contradição está na raiz das variações que se observam naquilo que, de tempos em tempos, se chama de natureza humana. No Caderno 16, $\$ 12$, pode-se ler:

A "natureza" do homem é o conjunto das relações sociais, que determina uma consciência historicamente definida; só esta consciência pode indicar o que é "natural" ou "contra a natureza". Além disso, o conjunto das relações sociais é contraditório a cada momento e está em contínuo desenvolvimento, de modo que a "natureza" do 
homem não é algo homogêneo para todos os homens em todos os tempos [nesta passagem, quer situar o que é natural e contra a natureza]. [...] Constatado que, sendo contraditório o conjunto das relações sociais, não pode deixar de ser contraditória a consciência dos homens, põe-se o problema de como se manifesta tal contradição e de como se pode obter progressivamente a unificação: manifesta em todo o corpo social com a existência de consciências históricas de grupo (com a existência de estratificações correspondentes a fases diversas do desenvolvimento da civilização e com antíteses nos grupos que correspondem a um mesmo nível histórico) e [como] se manifesta nos indivíduos particulares como reflexo de uma tal desagregação "vertical e horizontal". Nos grupos subalternos, por causa da ausência de autonomia na iniciativa histórica, a desagregação é mais grave e é mais forte a luta para se libertarem dos princípios impostos e não propostos, para obter uma consciência histórica autônoma [...] (Idem, p. 51).

Essa passagem permite inúmeras reflexões no campo da sociologia do conhecimento, mas obriga, também, a que se atente para a circunstância de que estamos diante de uma preocupação situada no cerne de algumas escolas sociológicas. Trata-se de um problema que se impõe a todos nós quando nos voltamos para o estudo da sociedade: Como se dá a unificação das consciências históricas dos diferentes grupos, isto é, como se pode observar a existência de valores comuns a todos os grupos, única forma de chegarse à unificação das consciências numa sociedade cheia de contradições, em que cada grupo tem sua consciência histórica, sua própria concepção de como se situa e se situou na sociedade? Mais ainda: essa consciência histórica, afora se referir a "passado e presente" (como ele nomeia em muitos momentos de seus Cadernos), exprime valores que, unificadas as consciências históricas, são próprios dos grupos dominantes e se transmitem para os subordinados. Como se dão essa unificação e passagem dos dominantes, isto é, dos dirigentes para os subordinados? Todo o problema da hegemonia reside aí, e disso decorre a importância das reflexões de Gramsci para a sociologia política e a história da cultura.

Uma primeira indicação de como se dá essa unificação pode ser encontrada no Caderno 13,
\$30: "As idéias e opiniões não 'nascem' espontaneamente no cérebro de cada indivíduo; tiveram um centro de formação, de irradiação, de difusão, de persuasão; houve um grupo de homens ou até mesmo uma individualidade que as elaborou e apresentou na forma política da atualidade" (Idem, 2000a, p. 82). Cabe ver que esse "grupo de homens" tanto pode ser um partido, tomada a palavra em sentido amplo, como um indivíduo Benedetto Croce, um "comitê de propaganda" - e o Estado. Ao cuidar, no mesmo Caderno 13, agora $₫ 7$, da questão do "homem coletivo ou do conformismo social", Gramsci escreveu:

Tarefa educativa e formativa do Estado, cujo fim é sempre o de criar novos e mais elevados tipos de civilização, de adequar a "civilização" e a moralidade das mais amplas massas populares às necessidades do contínuo desenvolvimento do aparelho econômico de produção e, portanto, de elaborar também fisicamente tipos novos de humanidade. Mas como cada indivíduo singular conseguirá incorporar-se no homem coletivo e como ocorrerá a pressão educativa sobre cada um para obter seu consenso e sua colaboração, transformando em "liberdade" a necessidade e a coerção? Questão do "direito", cujo conceito deverá ser ampliado, nele incluindo aquelas atividades que hoje são compreendidas na fórmula "indiferente jurídico" e que são do domínio da sociedade civil, que atua sem "sanções" e sem "obrigações" taxativas, mas que nem por isso deixa de exercer uma pressão coletiva e de obter resultados objetivos de elaboração nos costumes, nos modos de pensar e de atuar, na moralidade etc. (Idem, pp. 23ss.).

A parte final desse trecho não lembra a "coerção" e as "maneiras de ser, agir e pensar" que caracterizavam, para Durkheim, o fato social e as instituições?

No Caderno 24, \3, o problema volta a apresentar-se, mas com cuidados devidos à compreensão do que significa a existência, na sociedade, de diferentes grupos sociais:

A elaboração nacional unitária de uma consciência coletiva homogênea requer múltiplas condições e iniciativas. A difusão, por um centro homogêneo, de um modo de pensar e de agir homogêneo é a condição principal, mas não deve e não pode ser a única. Um erro muito difundido consiste em pen- 
sar que toda camada social elabora sua consciência e sua cultura do mesmo modo, com os mesmos métodos, isto é, com os métodos dos intelectuais profissionais. O intelectual é um "profissional" (skilled) que conhece o funcionamento de suas próprias "máquinas" especializadas; tem seu "tirocínio" e seu "sistema Taylor" próprios. É pueril e ilusório atribuir a todos os homens esta capacidade adquirida e não inata, do mesmo modo como seria pueril supor que todo operário manual possa desempenhar a função do maquinista ferroviário. É pueril pensar que um "conceito claro", difundido de modo oportuno, insira-se nas diversas consciências com os mesmos efeitos "organizadores" de clareza difusa: este é um erro "iluminista”. A capacidade do intelectual profissional de combinar habilmente indução e dedução, de generalizar sem cair no formalismo vazio, de transferir certos critérios de discriminação de uma esfera a outra do julgamento, adaptando-os às novas condições etc., constitui uma "especialidade", uma "qualificação", não é um dado do senso comum. É por isso, portanto, que não basta a premissa da "difusão orgânica, por um centro homogêneo, de um modo de pensar e de agir homogêneo". O mesmo raio luminoso, passando por prismas diversos, dá refrações de luz diversas: se se pretende obter a mesma refração, é necessária toda uma série de retificações nos prismas singulares (Idem, 2000, p. 205).

Essa idéia parece-me da maior importância, pois a noção do "raio luminoso" reforça tudo que se disse sobre as diferentes concepções do mundo, as diferentes concepções da história. Ela permite compreender como os diferentes grupos sociais, construindo suas concepções da história, apesar disso e da diferença que existe entre elas, apresentam maneiras de pensar que têm uma origem comum, podendo, no entanto, variar de grupo para grupo e, o que é mais importante, de indivíduo para indivíduo na sua manifestação exterior. Decorre da refração assinalada a dificuldade de estabelecer-se a hegemonia de um grupo sobre os demais, especialmente quando, nos grupos subordinados, há intelectuais capazes de contrapor a sua concepção da história àquela que se pretende dominante e dirigente.

Os intelectuais, como estabelecido no Caderno $12, \S 1$, desempenham papel fundamental na tarefa de unificar as diferentes consciências históricas, as diversas concepções do mundo apesar das dificuldades apontadas. A importância que Gramsci lhes atribui permite remeter ao Lênin do Que fazer?. A rigor, estamos diante de uma paráfrase (enriquecida) do que Lênin cita de Kautsky ao comentar o programa do Partido Socialista austríaco e o papel dos intelectuais na transmissão dos conhecimentos da ciência mais moderna (a economia política marxista) aos setores do proletariado mais capacitados intelectualmente:

De fato [afirma Gramsci], a atividade intelectual deve ser diferenciada em graus também do ponto de vista intrínseco, graus que, nos momentos de grande oposição, dão lugar a uma autêntica diferença qualitativa: no mais alto grau devem ser postos os criadores das várias ciências, da filosofia, da arte etc.: no mais baixo, os mais modestos "administradores" e divulgadores da riqueza intelectual já existente, tradicional, acumulada. [E continua:] No mundo moderno, a categoria dos intelectuais, assim entendida, ampliou-se enormemente. Foram elaboradas, pelo sistema social democráticoburocrático, imponentes massas, nem todas justificadas pelas necessidades sociais da produção, ainda que justificadas pelas necessidades políticas do grupo fundamental dominante (Idem, pp. 21ss.).

São dois os objetos de consideração que se apresentam, pois, quando se trata de estudar a unificação das consciências históricas; unificação essa que traduz a direção intelectual, moral e política do processo, e que vem a caracterizar de fato a hegemonia: partido e intelectuais. Não se trata, como poderia parecer, de questões atinentes à ciência política; pertencem à sociologia, pois aquela necessita desta para construir seus postulados. Não era essa a posição de Auguste Comte ao classificar as ciências, trazendo a política para o ápice da pirâmide, logo depois da sociologia, que se seguia à psicologia e à biologia? Deixemos as questões de prioridades, porém, e nos dediquemos às análises de Gramsci.

Partido e intelectuais aparecem em íntima relação no Caderno 12, $\$ 1$ :

Que todos os membros de um partido político devam ser considerados como intelectuais é uma afirmação que pode se prestar à ironia e à caricatura; contudo, se refletirmos bem, nada é mais exato. Será preciso fazer uma distinção de graus: um partido poderá ter uma maior ou menor com- 
posição do grau mais alto ou mais baixo, mas não é isto que importa: importa a função, que é diretiva e organizativa, isto é, educativa, isto é, intelectual (Idem, p. 25).

Antes, havia enunciado o mesmo tema:

O que se torna o partido político em relação ao problema dos intelectuais? [...] 2) o partido políti$\mathrm{co}$, para todos os grupos, é precisamente o mecanismo que realiza na sociedade civil a mesma função desempenhada pelo Estado, de modo mais vasto e mais sintético, na sociedade política, ou seja, proporciona a soldagem entre intelectuais orgânicos de um dado grupo, o dominante, e intelectuais tradicionais [...] (Idem, p. 24).

Haveria muito mais a dizer nesta tentativa de reconstruir o pensamento de Gramsci a partir dos elementos sociológicos que encontramos nos $\mathrm{Ca}$ dernos do cárcere, o que, infelizmente, não é possível no espaço restrito deste artigo.

\section{BIBLIOGRAFIA}

GRAMSCI, Antonio. (1950), Cartas del cárcere. Edição de Gregório Bermann. Buenos Aires, Lautaro.

(1999), Cadernos do cárcere, vol. 1: Introdução ao estudo da Filosofia; A filosofia de Benedetto Croce. Editado por Carlos Nelson Coutinho, Marco Aurélio Nogueira e Luiz Sérgio Henriques. Rio de Janeiro, Civilização Brasileira.

(2000), Cadernos do cárcere, vol. 2: Os intelectuais. Oprincípio educativo. Jornalismo. Editado por Carlos Nelson Coutinho, Marco Aurélio Nogueira e Luiz Sérgio Henriques. Rio de Janeiro, Civilização Brasileira.

. (2000a), Cadernos do cárcere, vol. 3: Maquiavel. Notas sobre o Estado e a política. Editado por Carlos Nelson Coutinho, Marco Aurélio Nogueira e Luiz Sérgio Henriques. Rio de Janeiro, Civilização Brasileira.

(2001), Cadernos do cárcere, vol. 4: Temas de cultura; Ação Católica; Ameri- canismo e fordismo. Editado por Carlos Nelson Coutinho, Marco Aurélio Nogueira e Luiz Sérgio Henriques. Rio de Janeiro, Civilização Brasileira.

(2002), Cadernos do cárcere, vol. 5: O Risorgimento; Notas sobre a bistória da Itália. Editado por Carlos Nelson Coutinho, Marco Aurélio Nogueira e Luiz Sérgio Henriques. Rio de Janeiro, Civilização Brasileira.

TROTSKY, Leon. (1948), 1905. Milão, Instituto Editorial Italiano. 


\section{A SOCIOLOGIA DE GRAMSCI}

Oliveiros S. Ferreira

Palavras-chave: Gramsci; Hegemonia; Sociologia; Ciência política; Urbano/rural.

Os Cadernos do cárcere podem ser vistos de uma perspectiva sociológica, vale dizer, é possível encontrar neles muitas lições de como estudar situações sociais e políticas à luz da sociologia clássica. Neste texto, busca-se mostrar como muitos dos ensinamentos da sociologia clássica, especialmente aqueles da Escola Francesa, podem ser encontrados nas meditações de Gramsci. Não se procura mostrar a influência da Escola Francesa sobre ele; pelo contrário, cuida-se de evidenciar que é possível encontrar nos Cadernos uma aguda visão sociológica, próxima daquilo que se encontra nos franceses, prova de que as idéias que informaram os franceses estavam presentes no pensamento de quantos estudavam a realidade a partir dela e não de idéias abstratas.

\section{THE SOCIOLOGY OF GRAMSCI}

Oliveiros S. Ferreira

Keywords: Gramsci; Hegemony; Sociology; Political science; Urban/rural.

The Cadernos do cárcere can be seen from a sociological perspective. It is possible to find in them many lessons on how to study social and political situations in the light of the classical sociology. This paper aims at showing how many of the teachings on classical sociology, especially those of the French School, can be found in the meditations of Gramsci. There is no worry in showing the influence of the French School in it; au contraire, care is given to enhance the possibility of finding in the Cadernos an acute sociological view, nigh to what is found in the French, proving that the ideas informed by the French were present in the thoughts of those who were studying the reality from itself, not from abstract ideas.

\section{LA SOCIOLOGIE DE GRAMSCI}

Oliveiros S. Ferreira

Mots-clés: Gramsci; Hégémonie; Sociologie; Sciences politiques; Urbain/rural.

Les Cadernos do cárcere (Cahiers de prison) peuvent être vus sous une perspective sociologique, c'est-àdire, il est possible d'y retrouver plusieurs leçons de comment étudier des situations sociales et politiques à la lumière de la sociologie classique. Dans ce texte, nous tentons de démontrer de quelle façon plusieurs des enseignements de la sociologie classique - particulièrement celles de l'École Française - peuvent être retrouvés dans les méditations de Gramsci. Nous ne cherchons pas à démontrer l'influence qu'a eu sur lui l'École Française. Au contraire : nous tentons de montrer qu'il est possible de trouver, dans les Cahiers, un point de vue sociologique proche de ce que l'on retrouve chez les français, ce qui prouve que les idées qui ont informé les français étaient présentes dans la pensée de tous ceux qui, à partir d'elles, étudiaient la réalité et non les idées abstraites. 